\title{
2 METODA SIGNIFIKAN PENDONGKRAK POSISI DOMAIN PADA MESIN PENCARI
}

\author{
Ibnu Gunawan \\ Fakultas Teknologi Industri, Jurusan Teknik Informatika, Universitas Kristen Petra \\ Jl. Siwalankerto 121 - 131, Surabaya 60236, Indonesia \\ E-mail: ibnu@petra.ac.id
}

\begin{abstract}
ABSTRAK: Dengan berbasis data survey dari lembaga survey internet independent di Amerika bernama pewinternet per tanggal 6 agustus 2008 oleh Deborah Fallow yang menyatakan bahwa aktivitas penggunaan mesin pencari adalah aktivitas pengguna internet nomor dua terbesar setelah e-mail, maka tidak dapat dipungkiri bahwa kunci sukses utama sebuah website adalah bagaimana domain website tersebut tercantum di urutan pertama pada daftar hasil pencarian sebuah mesin pencari. Salah satu cara untuk memastikan hal tersebut adalah dengan mempunyai SEO score yang tinggi. Hal ini membuat penulis tertarik untuk mengadakan eksperiment terhadap hubungan SEO score dan ranking sebuah domain dalam mesin pencari. Eksperiment dilakukan dalam kelas kuliah e-bisnis, dimana ada 6 kelompok dengan masing - masing domainnya yang kemudian dioptimalkan SEO nya. Hasil yang didapatkan sungguh mengejutkan, ternyata SEO score yang tinggi tidak menjamin ranking yang tinggi dan posisi puncak dari daftar sebuah mesin pencari. Jurnal ini akan menjelaskan secara detail bagaimana hal tersebut dilakukan.
\end{abstract}

Kata kunci: Mesin pencari, website, SEO, domain.

\begin{abstract}
Based on data from the Internet survey from independent institutions in the United States named pewinternet as on 6 August 2008 by Deborah Fallow stating that using search engine is the second largest activity of the Internet user after e-mail, so it can not be denied that the main key to the success of a website is how the website domain listed first on the search results of a search engine. One way to ensure this is to have a high SEO score. This makes the writer is interested to conduct experiments on the relationship SEO score and ranking of a domain in search engines. Experiments carried out in an ebusiness lecture class, where there are 5 groups with their own domain and then we optimized their SEO. The results obtained were surprising, it turns out that high SEO score does not guarantee a high ranking and the top of the list of a search engine. This journal will explain in detail how it is done.
\end{abstract}

Keywords: Search engine, website, SEO, domain

\section{PENDAHULUAN}

SEO atau yang lebih dikenal dengan Search Engine Optimization adalah sebuah proses mendesain webpage untuk mengoptimalkan potensinya sehingga bisa mencapai ranking tertinggi dalam sebuah mesin pencari, lebih disukai jikalau masuk pada halaman pertama [1]. Mesin pencari yang dipilih sebagai acuan adalah Google. Google dipilih karena merupakan search engine yang menguasai pasar semenjak tahun 2008 [2]. Dikarenakan mesin pencari yang menjadi acuan adalah Google, maka metoda optimasi SEO juga mengikuti petunjuk dari Google [3]. Metoda optimasi ini dibagi dalam 3 kategori yaitu kategori desain dan isi web, kategori teknikal, dan yang terakhir adalah kategori kualitas. Eksperimen dilaksanakan pada 5 domain yaitu: www.consandcloth. com, www.noblearchery.com, www.mini4wdspeed. com, www.surabaya-sulam. com, www.strawberrystore. com.
Selain menggunakan guideline resmi dari Google, beberapa web ada yang menerapkan adsense dan pay per click seperti pada www.constandcloth. com untuk mendatangkan traffic masuk sehingga menambah kemungkinan untuk di kenal oleh pengguna internet.

Ada juga yang membeli traffic masuk menggunakan backlink seperti pada www.noblearchery. com dengan tujuan sama seperti adsense dan pay perclick. Ataupun menggunakan bantuan media forum online seperti facebook dan kaskus untuk membantu memperkenalkan domain nya

Metoda lain yang dipakai adalah pendaftaran domain pada dmoz.org sehingga lebih mudah untuk dicari menggunakan mesin pencari seperti yang dilakukan oleh www.noblearchery.com

Penilaian SEO score dan relevansi didasarkan pada domain tools dari www.whois.sc yang sudah umum dipakai dikalangan web master. 


\section{PENELITIAN SEBELUMNYA}

Penelitian ini merupakan kasus lain sekaligus kelanjutan dari penelitian yang dilakukan oleh Bimal Pratap Shah pada tahun 2009 [1] dengan studi kasus pada web promosi turis di nepal. Penelitian kali ini bertujuan untuk mencari signifikansi dari metoda metoda optimasi SEO yang diberikan oleh Google terhadap hasil yang diperoleh pada page rank Google.

Selain itu ada penelitian tentang Open Directory Project (ODP) yang dilakukan oleh Paul - Alexandra Chirita dan ke-3 rekannya pada tahun 2005 [4]. Penelitian ini mencatat bahwa Google menggunakan ODP sebagai dasar dari Google Directory Service.

\section{METODE}

Berikut adalah metoda optimasi SEO Google yang digunakan pada penelitian kali ini berdasar pada 2 paper sebelumnya.

\section{Domain}

Menurut pedoman optimasi SEO dari Google, sangat disarankan untuk menggunakan nama domain yang lugas dan sangat mencerminkan apa isi dari web.

Sebagai contoh, jika web berisi informasi seputar pariwisata maka nama domain yang cocok adalah touristinfo atau exoticplaces. Selain itu, jika web digunakan untuk berjualan maka .com akan sangat cocok digunakan dibandingkan net atau .biz. Karena .com memang di reservasi atau di siapkan untuk domain domain yang digunakan untuk berbisnis.

\section{Title}

Tag <title> yang ada pada setiap halaman depan sebuah web site sangat lah penting untuk bisa relevan dengan isi web secara keseluruhan serta menarik untuk dikunjungi.

Sebagai contoh jika web berisi informasi seputar pariwisata maka judul yang cocok diantaranya adalah best holiday destination. Bila perlu judul ini unik untuk tiap halaman web yang ada namun konvergen ke 1 keseluruhan isi web.

\section{Meta tag}

Meta tag berguna untuk memberikan rangkuman untuk isi tiap halaman web. Meta tag ini penting dikarenakan akan digunakan oleh Google untuk memberikan ringkasan yang ada di setiap hasil pencarian yang disajikan untuk user.
Oleh karena itu sangat baik sekali jika meta tag ini diisi penjelasan yang ringkas dan jelas terhadap apa isi dari sebuah halaman web, khususnya halaman depan. Misalnya untuk web yang memberikan informasi pariwisata maka meta tagnya adalah Anda dapat menemukan informasi terbaik tentang tempat tempat berlibur di seluruh dunia sesuai dengan budget yang Anda inginkan.

Selain 3 point guideline resmi Google, ada pula metoda lain yang tidak resmi namun terbukti bisa meningkatkan rangking pada mesin pencari. Ke-3 point itu diantaranya:

\section{Adsense}

Metoda ini memberikan tempat pada domain lain di domain kita untuk ikut mengiklankan produk mereka dan sebaliknya, domain kita juga ikut diiklankan di domain lain itu. Harapannya adalah domain kita bisa ikutan populer seperti domain lain yang terdaftar di adsense. Yang otomatis meningkatkan rank Google nya.

\section{PayPerClick}

Metoda ini memberikan bayaran tiap kali user mengklik banner yang ada pada domain kita. Jadi diharapkan user/penjelajah internet tertarik membuka domain kita karena bisa menghasilkan uang. Yang otomatis meningkatkan rank Google nya.

\section{Backlink}

Metoda ini memberikan aliran traffic masuk yang sangat besar ke domain kita sesuai dengan kesepakatan harga yang dibayar. Keistimewaan dari metoda ini adalah metoda ini membuat domain kita sering di cari pada mesin pencari, sehingga otomatis rank nya akan naik sendiri.

\section{ODP}

Metoda ini mempermudah mesin pencari menemukan domain kita dengan melakukan public listing pada direktori domain online pada server server besar di dunia. Salah satunya adalah pada dmoz.org. hal ini dikarenakan DMOZ.ORG adalah ODP (Open Directory Project) yang paling besar, paling komprehensif, yang pernah ada. Dengan statistik sebagai berikut:

1. Meliputi 4 miliar situs yang terbagi dalam

2. 590000 kategori dengan 16 kategori teratas dan tersebar secara rata seperti seni, komputer, warta, olahraga dan lainnya.

3. Dan di maintain oleh 65000 sukarelawan yang tersebar di seluruh penjuru dunia. 
Dengan melakukan public listing ini maka ranking sebuah situs pada mesin pencari Google akan meningkat secara signifikan dikarenakan penentuan page rank Google pada tahap pertama adalah mencari situs situs yang telah terdaftar pada Google directory service. Sedangkan Google directory service sendiri mendasarkan listnya pada dmoz.org.

\section{PENERAPAN}

Berikut ini akan dipaparkan bagaimana ke-3 prinsip tersebut diterapkan dalam 5 website yang berbeda.

\section{www.Constandcloth.com}

Domain ini digunakan untuk berjualan alat konstruksi (const) dicampur dengan baju (cloth). Oleh karena itu bernama constandcloth. Title/judul pada domain ini adalah Const And Cloth Pusat Belanja Baju Online Terlengkap. Dikarenakan judulnya bagus maka mendapat penilaian relevansi judul sebesar $100 \%$ dari domain tools www.whois.sc.

Domain ini menggunakan meta tag sebagai berikut : "Web Const And Cloth ini menjual baju dan alat pengukur untuk bangunan, dimana web ini menjual dengan harga yang murah". Yang kemudian mendapatkan nilai relevansi $35 \%$ dari domain tools www.whois.sc.

Selain menerapkan guideline dari Google, constandcloth juga mendaftarkan diri ke adsense dan pay per click, agar lebih bisa dikenal orang.

Total nilai seo untuk web ini dari domain tools www.whois.sc adalah sebesar 57\% per tanggal 17 maret 2011. Pada pukul 15.49 WIB

\section{www.hk-852.com}

Domain ini digunakan untuk berjualan barang barang yang aneh dan unik. Oleh karena itu nama domain nya juga aneh dan unik yaitu hk-852. Title / judul pada domain ini adalah website ini menyediakan berbagai macam pernak-pernik dengan harga yang wajar dengan kualitas yang didapatkan. Dikarenakan judulnya bagus maka mendapat penilaian relevansi judul sebesar $100 \%$ dari domain tools www.whois.sc.

Domain ini menggunakan meta tag sebagai berikut : "pernak-pernik, celengan, lampu-hias, asbak, toko-pernak-pernik, celengan-lucu, mainan, gantungankunci, tempat-rokok, pasar-atom". Yang kemudian mendapatkan nilai relevansi $41 \%$ dari domain tools www.whois.sc.

Total nilai seo untuk web ini dari domain tools www.whois.sc adalah sebesar $92 \%$ per tanggal 17 maret 2011.

\section{www.mini4wd.com}

Domain ini digunakan untuk berjualan spare part mini 4wd. Oleh karena itu nama domain nya adalah mini4wd. Title/judul pada domain ini adalah mini4wd.com - Sumber dan Informasi mini 4wd terbaik. website ini untuk jual!. Dikarenakan judulnya tidak relevan (web nya menjual sparepart namun title nya sebagai pemberi informasi) maka mendapat penilaian relevansi judul sebesar $41 \%$ dari domain tools www.whois.sc.

Domain ini tidak menggunakan meta tag sama sekali. Namun domain ini mempromosikan dirinya pada beberapa media online seperti kaskus dan facebook

Total nilai seo untuk web ini dari domain tools www.whois.sc adalah sebesar $66 \%$ per tanggal 17 maret 2011.

\section{www.noblearchery.com}

Domain ini digunakan untuk berjualan peralatan memanah. Oleh karena itu nama domain nya adalah noblearchery. Title/judul pada domain ini adalah Noble Archery - Jual Panah, Toko Panah, Panah Tradisional. Dikarenakan judulnya bagus maka mendapat penilaian relevansi judul sebesar $100 \%$ dari domain tools www.whois.sc.

Domain ini menggunakan meta tag sebagai berikut: "Noble Archery - Jual Panah, Toko Panah, Panah Tradisional" Yang kemudian mendapatkan nilai relevansi $100 \%$ dari domain tools www.whois. sc.

Selain menggunakan metoda yang umum, domain ini juga menggunakan beberapa metoda lain seperti membeli backlink dan me public listingkan dirinya pada dmoz.org.

Total nilai seo untuk web ini dari domain tools www.whois.sc adalah sebesar $76 \%$ per tanggal 17 maret 2011.

\section{www.strawberry-store.com}

Domain ini digunakan untuk berjualan baju wanita, semacam butik online, oleh karena itu nama domain nya adalah strawberry-store. Mengapa memilih strawberrystore? Dikarenakan pada umumnya wanita menyukai strawberry, maka toko ini bernama strawberry store. Title/judul pada domain ini adalah Butik Online | Butik Online Murah Indonesia | Butik Baju Wanita Indonesia | Grosir tas, baju, dan aksesoris wanita - Strawberry Store. Dikarenakan judulnya bagus maka mendapat penilaian relevansi judul sebesar $100 \%$ dari domain tools www.whois.sc. 
Domain ini menggunakan meta tag sebagai berikut: "Strawberry Store Butik Online Murah Indonesia Grosir, tas, baju, dan aksesoris wanita" Yang kemudian mendapatkan nilai relevansi $100 \%$ dari domain tools www.whois.sc.

Total nilai seo untuk web ini dari domain tools www.whois.sc adalah sebesar $90 \%$ per tanggal 17 maret 2011.

\section{www.surabaya-sulam.com}

Domain ini digunakan untuk berjualan hasil sulaman. Home - Surabaya-Sulam. Dikarenakan judulnya sangat sederhana maka domain ini mendapat penilaian relevansi judul sebesar $0 \%$ dari domain tools www.whois.sc.

Domain ini menggunakan meta tag sebagai berikut: "Shop powered by PrestaShop" Yang kemudian mendapatkan nilai relevansi $100 \%$ dari domain tools www.whois.sc.

Total nilai seo untuk web ini dari domain tools www.whois.sc adalah sebesar $83 \%$ per tanggal 17 maret 2011.

\section{HASIL DAN DISKUSI}

Penerapan metoda optimasi SEO pada kelima domain tersebut membuahkan hasil yang beragam. Untuk melakukan penilaian, penguji melakukan pencarian pada mesin pencari menggunakan keyword yang sama dengan tag title pada domain web yang bersangkutan atau kalau tidak ada isi pada tag title nya, maka penguji akan mencarinya berdasarkan keyword yang relevan untuk barang atau jasa yang dijual oleh domain yang bersangkutan.

Ujian pertama dilakukan untuk domain www. Constandcloth.com. Title untuk domain ini adalah "Const And Cloth Pusat Belanja Baju Online Terlengkap." Oleh karena itu ujian dilakukan dengan mencoba 3 macam kombinasi keyword yaitu: "Belanja Baju Online", "Pusat Belanja Baju Online" dan "Pusat Belanja Baju Online Terlengkap". Pada 3 kali pengujian ini, domain constandcloth tidak muncul pada halaman depan mesin pencari www.google.co.id.

Ujian ke dua dilakukan pada domain www.hk852.com. Title untuk domain ini adalah "hk-852." Sehingga diputuskan tidak layak untuk digunakan sebagai keyword. Sehingga penguji mencoba dengan keyword yang mencerminkan barang apa yang dijual oleh www.hk-852.com. Ujian dilakukan dengan mencoba 3 macam kombinasi keyword yaitu: "pernak pernik", "jual pernak pernik" dan "toko pernak pernik". Pernak pernik di sini diambil dari meta tag yang ada pada domain www.hk-852.com. Diharap- kan pengujian ini berhasil menempatkan hk-852.com pada halaman pertama di mesin pencari google.co.id. Ternyata pada 3 kali pengujian ini, domain hk-852 tidak muncul pada halaman depan mesin pencari www.google.co.id.

Ujian ke tiga dilakukan pada domain www. mini4wd.com. Title untuk domain ini adalah "mini4wd.com - Sumber dan Informasi mini 4wd terbaik.". Ujian dilakukan dengan mencoba 3 macam kombinasi keyword yaitu: "mini4wd", "mini4wd terbaik" dan "informasi mini4wd terbaik". Diharapkan pengujian ini berhasil menempatkan mini4wd. com pada halaman pertama di mesin pencari google.co.id. Ternyata pada 3 kali pengujian ini, domain mini4wd tidak muncul pada halaman depan mesin pencari www.google.co.id.

Ujian ke empat dilakukan pada domain www. noblearchery.com. Title untuk domain ini adalah "Noble Archery - Jual Panah, Toko Panah, Panah Tradisional.". Ujian dilakukan dengan mencoba 3 macam kombinasi keyword yaitu : "jual panah", "jual panah tradisional" dan "panah tradisional". Diharapkan pengujian ini berhasil menempatkan noblearchery.com pada halaman pertama di mesin pencari google.co.id. Ternyata pada 3 kali pengujian ini, sesuai dugaan domain noblearchery muncul pada halaman depan mesin pencari www.google.co.id.

Ujian ke lima dilakukan pada domain www. strawberry-store.com. Title untuk domain ini adalah "Butik Online | Butik Online Murah Indonesia Butik Baju Wanita Indonesia | Grosir tas, baju, dan aksesoris wanita - Strawberry Store.”. Ujian dilakukan dengan mencoba 3 macam kombinasi keyword yaitu: "butik online", "jual baju wanita" dan "butik baju wanita". Diharapkan pengujian ini berhasil menempatkan www.strawberry-store.com pada halaman pertama di mesin pencari google.co.id. Ternyata pada 3 kali pengujian ini, domain strawberry-store tidak muncul pada halaman depan mesin pencari www.google. co.id.

Ujian ke enam dilakukan pada domain www. surabaya-sulam.com. Title untuk domain ini adalah "www.surabaya-sulam.com.". Sehingga diputuskan tidak layak untuk digunakan sebagai keyword. Sehingga penguji mencoba dengan keyword yang mencerminkan barang apa yang dijual oleh www. surabaya-sulam.com. Ujian dilakukan dengan mencoba 3 macam kombinasi keyword yaitu: "jual sulam", "sulam surabaya" dan "sulaman". Pernak pernik di sini diambil dari meta tag yang ada pada domain www.surabaya-sulam.com. Diharapkan pengujian ini berhasil menempatkan surabayasulam.com pada halaman pertama di mesin pencari google.co.id. Ternyata pada 3 kali pengujian ini, domain surabaya-sulam tidak muncul pada halaman depan mesin pencari www.google.co.id. 
Dari ke enam hasil ujian tersebut, terlihat bahwa relevansi dari tag title dan meta keyword tidak berpengaruh banyak pada kesuksesan merebut tempat di halaman pertama Google. Sekaligus justru membuktikan keampuhan penggunaan public listing pada dmoz.org untuk mendapatkan hasil yang cukup membanggakan pada Google.

\section{KESIMPULAN}

Relevansi dari tag title dan meta keyword tidak berpengaruh banyak pada kesuksesan merebut tempat di halaman pertama Google.

Metoda backlink yang digabungkan dengan public listing melalui dmoz.org sangat efektif dalam mendongkrak posisi domain pada page rank Google. Ini sesuai dengan temuan Heymann [5] yang dituangkan dalam paper yang berjudul "Can social bookmarking improve web search?" pada proceeding of the international conference on Web search and web data mining dan didukung oleh penemuan tentang bagaimana menggunakan ODP untuk mempersonalisasikan pencarian oleh Chirita [4].
Sayangnya penggunaan media online seperti facebook dan twitter belum digunakan namun diganti dengan menggunakan back link.

\section{DAFTAR PUSTAKA}

1. Shah, B., 2009, Search engine visibility of national tourism promotion websites: a case of Nepal, November 2009, ICEGOV '09: Proceedings of the 3rd international conference on Theory and practice of electronic governance

2. Dorrestiejn, J. 2008, The World Wide Web is growing a billion pages per day, Accessed on 28 March 2009 at: http://thenextweb.com/2008/07/ 29/the-world-wide-webgrows-a-billion-pages-perday/

3. Google, 2010, search engine optimization starter guide.

4. Chirita, P.A., Nejdl, W., Paiu, R., and Kohlschutter, C., 2005, Using ODP metadata to Personalize search, SIGIR 2005, Brazil.

5. Heymann, P., 2008, Can social bookmarking improve web search?, WSDM '08: Proceedings of the international conference on Web search and web data mining. 